\title{
Who does what in the pathology laboratory?
}

\author{
EVA LESTER
}

The debate about the role of clinical pathologists has occupied pathologists for over a decade, certainly, and probably, not coincidentally, since the division of clinical pathology into haematology, microbiology, and chemical pathology posts. It has surfaced from time to time in the columns of clinical medical journals and is apparently now taxing the minds of medical laboratory scientific officers. ${ }^{1}$ It is perhaps curious that with the changes in laboratory practice no one seems to be prepared to admit that it is the medical laboratory scientific officers whose role needs to undergo the most radical change. Since pathologists, however, have been indulging in the futile practice of fiddling while Rome burns it is unreasonable to blame any other group.

\section{Disappearance of clinical pathologists}

During the course of the debate, the problem of clinical pathologists has diminished with the diminution in their numbers and is about to disappear with their disappearance from their laboratories. It is true that recently the Royal College of Pathologists has been concerned about the lack of trainees but, again, it is no coincidence that the concern has been expressed by college officers who are histopathologists. ${ }^{2}$ Histopathologists have a clearly defined role in providing a service to clinicians that, as yet, no other group of workers have the training or inclination to usurp.

In my own region, North-east Thames, there are at present seven consultant chemical pathologists in the 13 non-teaching districts with non-medical biochemists in charge in the other districts. (In the four teaching hospitals there are eight consultants in post and two vacancies.) In Yorkshire there are only four consultant chemical pathologists in 16 districts. In microbiology, where there have not so far been the same opportunities for non-medical science graduates, there are five unfilled vacancies in the North-east Thames region with presumably medical laboratory scientific officers in charge. In haematology, nationally, a different solution has emerged. Haematologists who have found themselves a clinical role, even though not an entirely satisfactory one, have quietly abdicated from the day-to-day management of their laboratories without upsetting any one except those who are providing or sharing the already meagre clinical facilities.

The Royal College of Pathologists suggests that the creation of more training posts might solve the problem. It will be interesting to see whether its attempts to persuade regional administrators and clinicians to divert money to such posts are

North Middlesex Hospital, London N18 1QX

EVA LESTER, MB, MRCPATH, consultant chemical pathologist successful and even more interesting to see whether, if such posts are created, they can be filled.

\section{Demarcation lines}

As a chemical pathologist in a district general hospital I am concerned that not only non-medical scientists and medical laboratory scientific officers but also the Royal College of Pathologists seem to accept as a self-evident truth that it is possible to draw a line of demarcation between my responsibilities-clinical and looking out of the laboratory-and those of non-medical staff-scientific and looking into the laboratory. I do not believe that there is any potential for real clinical involvement by pathologists who, although they are medically qualified, have not had a postgraduate clinical training and who do not have real clinical responsibility for real patients. The job of a pathologist is the organisation and management of the laboratory service, and it is because he has a medical background that other things being equal he is the best person to relate the work of the laboratory to the needs of patients. Unfortunately most doctors are not interested in organisation and management, which is why there is difficulty in recruiting them into pathology (and incidentally why their voice in the organisation of health services as a whole is now so weak). Even some of those who become pathologists are unwilling to concern themselves with what they regard as trivial details. It is these details that differentiate a laboratory service from occupational therapy for pathology staff. Doctors should not then be surprised if medical laboratory scientific officers take over management while they are making music.

It may well be that the dialogue that should take place should be between non-medical graduate scientists, present in large numbers in clinical chemistry already and increasing steadily in microbiology and haematology, and those graduate medical laboratory scientific officers employed as "technicians" in all three departments. The Fulton Report raised this problem as long ago as 1968 when most laboratory technicians did not have degrees. ${ }^{3}$ Thirteen years later, when many do, it would be encouraging to see some progress.

In the next few years it will become increasingly difficult to man efficiently the factory assembly lines that our laboratories are becoming as a result of the failure of either pathologists or clinicians to limit investigations to those that might conceivably give useful information.

Since, however, the explosion in pathology work load has apparently burnt itself out recently, partly because of the reduction in acute hospital facilities and partly because we have almost reached saturation point when every patient in every hospital bed has every known test every day, we can no longer claim that every advance in automation is only enabling us to do the increased work load with the same numbers of technical staff. We could now manage with fewer medical laboratory scientific officers, and if we continue to employ large numbers of graduate medical laboratory scientific officers as machine minders it is 
hardly surprising if they use their minds to contemplate revolution. There are jobs in routine hospital pathology laboratories for only two groups of people: managers and technicians. While the three existing professions are squabbling over management no one seems concerned that we are no longer training technicians. The examination for the fellowship of the Institute of Medical Laboratory Sciences (the name is significant; it changed from the Institute of Medical Laboratory Technology in 1975) has papers on the clinical and organisational aspects of pathology. What it no longer includes is any practical examination of the technical competence of candidates, and in this it is unique among qualifying examinations for workers in the health service who are concerned with the clinical management of patients.

\section{References}

1 Burns JB. The changing face of the laboratory. Br Med 1981 ;282:1943-4. 2 Anderson JR, Tighe JR. Staffing crisis in pathology. Br Med F 1980;281 : 1370-2.

3 Fulton Committee. The Civil Service. Vol 1. Report of the Committee 1966-8. London: HMSO, 1968. (Cmnd 3638.)

(Accepted 6 fuly 1981)

\section{MATERIA NON MEDICA}

\section{Fight for survival}

Having last watched a soccer match as a lad more years ago than I care to remember, when Norwich City were struggling in the old Third Division (South) my resistance to spectating again was finally overcome by the pleadings of a football-crazy son.

At the time "United," after a disastrous start to the season, were struggling in an unhealthy position at the bottom of the Third Division, the undignified drop to the Fourth looking inevitable. Nothing daunted, our first expedition was on a bitterly cold night with the mist swirling over the pitch making play sporadically invisible. A helpful ex-patient in the ticket office anxious to help keep costs down directed us to part of the stand reserved for family groups. We shivered, despite being well wrapped up, and soon realised the purpose of the small flasks everybody, except us, had taken and envied them their half-time hot drink.

Amazingly the home team won and our loyal support continued as often as the emergency rota would permit. We quickly picked up the finer points of the game and were able knowingly to discuss the team fortunes with other devotees. Our range of insults to be shouted after fouls on home-team players and to obviously biased referees was considerably extended, particularly by tuition from the dedicated supporters coming from north of the border, who made the attempted invective by the locals sound complimentary.

The winning streak continued and United finished still in the Third Division. This near-miracle was generally attributed to a mid-season managerial change and the signing of an experienced striker from Sunderland. We know better, and regard it as our moral duty to be present when the 1981 season kicks off.-R H SALTER (consultant physician, Carlisle).

\section{Instant sunshine: from Edinburgh rags to $B B C$ riches}

The Edinburgh Fringe Festival must have almost as many performers as audience: all over the city in every room that can contain more than ten people, in the streets, on the roofs, and in the bars people are reciting from telephones directories, playing krummhorns, stripping, ritually disembowelling turnips, and doing anything to be noticed. Some troupes of 10 perform to embarrassed audiences of three, who slink away in the interval. After a. hard day on the boards and after the pubs have shut these performers all head for the Fringe Club, where you can drink until 3, pour scorn on the opposition, and rub shoulders with the momentarily famous. Many of the groups perform in the cabaret, hoping to tempt people along to swell their audiences or simply to revel in the glory of ministardom once more before they go back to being doctors, solicitors, students, and other unknowns. It was at the Fringe Club just after midnight sometime in August 1977 that I first really enjoyed the now well known group Instant Sunshine.

Performing at the Fringe Club is hard: most people are there to unwind after their shows, drink too much, and be seen. They are not interested in the cabaret. And for Instant Sunshine, who wear dinner jackets and are at least 10 years older than the average Fringe Club aficionado, you might think it would be impossible to catch the audience's attention. But absolutely not : they went down rather better than Bob Dylan might have done. Since that night they have never looked back. They have joined the ranks of John Cleese, the Beyond the Fringe team, and Rowan Atkinson all of whom first "made it" at the Edinburgh Fringe Festival.

Now four years later they are everywhere: on the television (on
Christmas Eve no less), on the radio, at the Queen Elizabeth Hall, and even in the $B M F$. They have just produced another record (EMI Note label: NTS $215, £ 4 \cdot 10$ ), which I unhesitatingly recommend to anybody with a sense of humour and swing, and now there is a book (The Instant Sunshine Book, £3.95, Robson Books), which contains "hints for struggling supergroups" as well as the music and words to many of their songs. Whether you are an established fan or one of the few people around who has not heard of this group (three of whom are doctors, and two of whom are outstandingly good looking) you are bound to enjoy something (if not everything) in the book or on the record.-RICHARD SMITH (London).

\section{Refresher course}

In retrospect I do not feel very proud of what happened. But just to set it down on paper partly exorcises my feeling of guilt. For the adventure can then be seen as it was, unavoidable, step following step with the sequence and logic of a dream.

It was 915 am on a perfect sunny day outside the postgraduate medical centre, and all the doctors were driving up with their smart cars, brief cases, and lounge suits. It was then the feeling came on me most strongly that I could not go in. It had been with me since daybreak, flitting in and out of my mind, persuading devilishly, driven away by common sense and propriety, always returning. What would my cousins say? How would the course organiser react? It had woken me at $6 \mathrm{am}$, forced me to pack and prepare the car for two different journeys, brought me down to breakfast absurdly dressed, the suit for one thing, the comical shirt, dredged from the bottom of a climbing rucksack for the other. The clothing betrayed my dichotomy of mind, and did not go unnoticed, though nothing was said.

There are days when the climbing fever (or obsession or what you will) rises up inside and has to be let out. This was one of those days. So I sent my wife into the refresher course, and drove off to Creag Meagaidh instead. What a day it was! The snowfields of Cairngorm were fairly sparkling in the sun as I drove south on the fine new road behind Aviemore. It took just over an hour to cover the 57 miles to Loch Lagganside. Ten minutes sufficed for a quick change into boots, gaiters, and anorak. There was no need to take a rope, for I was alone. This was just one of a number of mistakes made that day. For obvious reasons nobody knew my destination-I scarcely knew myself. I only knew that I must hurry, the day was short, and there was so much to do.

So I walked and half ran past the farm where a grisly fox lay dead across a barbed wire fence, and took the fine stalkers' path into Coire Ardair. At 10 minutes past noon I reached the foot of Raeburn's gully, put on crampons, stuck the two ice axes with their curved picks in the snow, and took a breath or two. The gully stretched upwards far away and soon disappeared from view behind a rocky corner. It was graded difficult in the MacInnes guide, with two stars for quality, but how difficult was difficult? A good question for a solo climber. Raeburn would have had to cut steps all the way up it, and so would we in the 1950 s, when tricouni nailed boots and slaters' hammers were still being used. Two modern axes and crampons made it seem quite easy, just a long hard slope of firm snow-ice at $50^{\circ}$ and an increasing sense of exposure near the top. It took only an hour.

After a pleasant walk to the summit of Creag Meagaidh I was back by the roadside by $430 \mathrm{pm}$ for a quick tea, and in Inverness by 6 .

"And what," said my cousin, "did you learn at the course today ?"H G NICOL (Stratford upon Avon, Warwickshire). 